\title{
$\$$

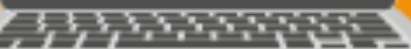

\section{GRADUAÇÃO EM DIREITO NA MODALIDADE DE EDUCAÇÃO A DISTÂNCIA: DESAFIOS, DILEMAS E POSSIBILIDADES}

\author{
Pollyana Vieira de Andrade \\ PUC-GO/BRASIL \\ pollyanavieiradeandrade@gmail.com \\ Nivaldo dos Santos \\ PUC-GO/BRASIL ${ }^{2}$ \\ nivaldodossantos@bol.com.br
}

Eixo 1 - Política, gestão e financiamento da educação a distância

\begin{abstract}
Resumo: O texto objetiva refletir e analisar sobre os desafios, dilemas e possibilidades da graduação em Direito na modalidade de educação a distância $(\mathrm{EaD})$, partindo da perspectiva da necessidade de ressignificar o modo como os cursos de Direito conduzem o processo educativo, buscando encontrar garantias para que se tenha um ensino eficiente e de qualidade. A metodologia adotada foi a pesquisa bibliográfica e documental, sendo considerados documentos da legislação do Ministério da Educação e Cultura sobre a modalidade da educação a distância.
\end{abstract}

Palavras-chave: Educação a distância. Graduação em Direito. Processo educativo.

\section{Introdução}

A educação é, sem dúvida, possibilidade de desenvolvimento das potencialidades humanas, da apropriação dos saberes sociais construídos historicamente, aquisição de

\footnotetext{
${ }^{1}$ Mestranda em Educação na Universidade Federal de Goiás. Especialista em Computação pela Pontifícia Universidade Católica de Goiás, Graduada em Administração Pública pela Pontifícia Universidade Católica de Goiás, Graduada em Administração de Empresa pela Pontifícia Universidade Católica de Goiás. Integrante do Grupo de Estudos e Pesquisas em Educação a Distância - GEaD - UFG/FE. Assessora Técnica da Pró-Reitoria de Graduação da Pontifícia Universidade Católica de Goiás /PUC-GO. Lattes:http://lattes.cnpq.br/1880573642186081. Orcid: https://orcid.org/0000-0002-8251-6558.

${ }_{2}^{2}$ Professor Titular na Pontifícia Universidade Católica de Goiás e Universidade Federal de Goiás. Doutor em Direito pela PUC/SP. Pós-Doutor em Direito pela PUC/MG. Lattes: http://lattes.cnpq.br/3359203015249134. Orcid: http://orcid.org/0000-0001-6184-5638.
}

III SEMINÁRIO DE EDUCAÇÃO A DISTÂNCIA 
conhecimentos e habilidades que permitem conhecer e compreender a realidade de modo a contribuir para sua transformação (SANTOS, 2018).

Nesse contexto, no que se refere ao campo da Educação Superior e suas modalidades, como a educação a distância $(\mathrm{EaD})$, percebe-se que há a necessidade de compreensão da educação como princípio vital para as relações sociais, políticas e institucionais.

Assim, sabe-se que a $\mathrm{EaD}$ no Brasil é parte significativa das políticas públicas educacionais, a qual define princípios, diretrizes, critérios e referenciais de qualidade para que as instituições de ensino superior ofereçam a modalidade. Os marcos considerados essenciais nesse processo são a publicação da Lei de Diretrizes e Bases da Educação (LDB) n. ${ }^{\circ}$ 9.394, de 1996, o Decreto n. ${ }^{\circ}$ 5.622, de 2005 e o Decreto n. ${ }^{\circ}$ 9.057, de 2017, dentre outros documentos, que influenciaram de forma significativa a configuração atual da educação a distância.

Nesse sentido, faz-se importante ressaltar que a modalidade de $\mathrm{EaD}$ tornou-se uma realidade e um desafio no Brasil. No que se refere ao processo de ensino-aprendizagem, percebe-se que a modalidade de $\mathrm{EaD}$ envolve, também, uma nova forma de aprender (estudante) e de ensinar (docente), na perspectiva da aprendizagem por meio das tecnologias (materiais didáticos e mídias).

Nota-se, portanto, que a modalidade de EaD é um tema bastante discutido no contexto da educação no Brasil, em função da sua acelerada expansão e, principalmente, em função do novo perfil do discente, inserido em uma sociedade em constantes transformações. Nesse sentido, compreende-se a necessidade de avaliar essa modalidade educativa e seus efeitos no âmbito das Escolas Jurídicas, apesar do tema ser bastante complexo e dividir opiniões no meio acadêmico.

Dessa forma, o presente texto tem por objetivo, proporcionar uma reflexão sobre os desafios, dilemas e possibilidades da graduação em Direito na modalidade de educação a distância (EaD), partindo da perspectiva da necessidade de ressignificar o modo como os cursos de Direito conduzem o processo educativo, buscando encontrar garantias para que se tenha um ensino eficiente e de qualidade. 


\section{Breve histórico do Ensino Jurídico no Brasil}

De acordo com Moura, Tassigny e Silva (2018), a implantação do ensino no campo do direito aconteceu em 1827, mas a instalação só ocorreu no ano seguinte, em São Paulo e em Olinda. (SILVA; SERRA, 2017, p. 2619). Fundada em 28 de março de 1828, o primeiro curso estava localizado no Convento de São Francisco, na capital paulista, e o segundo, criado em 15 de maio de 1828, em Olinda, no Mosteiro de São Bento.

No início do Século XX, em 1927, o desenvolvimento do curso gerou um número de 14 cursos de Direito, com um total de 3.200 alunos matriculados (SIQUEIRA, 2000, p. 2620). Assim, a primeira mais significativa reforma foi feita por Francisco Campos, em 1931, que institucionalizou a figura da universidade no Brasil (MOSSINI, 2010, p. 92).

Naquela época, surge a Ordem dos Advogados do Brasil (OAB), criada em 1930, em que foi elaborada a primeira Lei Federal 4.215/1963 (atualmente revogada), que ficou conhecida com o Estatuto da $\mathrm{OAB}$, apresentando os primeiros requisitos para o exercício da profissão, como as provas do exame de ordem (ao final do curso) ou a obrigatoriedade do estágio, quando ainda estudante, no último período (SILVA; SERRA, 2017, p. 2621).

Foi somente em 1994, devido à Portaria n¹.886/94 do Ministério da Educação, que houve exigências transformadoras para os estudantes do curso de direito, incluindo a exigência de nota mínima no exame de ordem, concomitantemente com outros requisitos, tais sejam: trabalho de conclusão de curso, estágio obrigatório etc (MOSSINI, 2010, p. 97-98). Havendo, entre outras alterações, mudanças nas grades curriculares pelo Artigo $3^{\circ}$ da resolução 9/2004 do Conselho Nacional de Educação (CNE), incluindo matérias com conteúdos relacionados à antropologia, ciências políticas, economia, ética, filosofia, entre outras.

Diante do início do curso, em 1928, até os dias atuais, quase 200 anos depois, fica evidente que há uma necessidade de readequação para superar problemas apresentados por uma sociedade global e em ritmo de mudanças, pois esta exige muito mais que habilidades cognitivas. Essas mudanças devem ocorrer em ambos os aspectos, tanto no que diz respeito a reformular e atualizar os currículos nas universidades, mas também na didática/metodologia da 
sala de aula, de modo a preparar os estudantes para as demandas impostas pelo mundo do trabalho (CHRISTENSEN; EYRING, 2014, p. 10).

Segundo Moura, Tassigny e Silva (2018), em um fluxo de contrassenso, ao invés de encontrar uma solução para elevar os níveis do curso de direitos, nos últimos anos, houve uma proliferação de faculdades, oferecendo o referido curso no Brasil. Isso ocorreu devido à autorização do Ministério da Educação (MEC), com dados que superam mais de 1000 cursos de direito autorizados (FOREQUE, 2013, p. 1), o que gerou, por consequência, um grande número de matrículas no curso, apesar do baixo número de concluintes, conforme os dados do Censo de Educação Superior, 2016.

Já, em maio de 2018, por meio da portaria n $^{\circ} 329$, o MEC autorizou mais de 5.000 vagas para o curso de direito, dentre as faculdades do Brasil. (BRASIL, 2018). A formação do profissional do Direito pelas faculdades deve levar em conta as Diretrizes Curriculares do Curso de Direito, elaborada pelo MEC, em que se afirma que o curso de direito deve assegurar uma graduação sólida, capaz de assegurar um bom desempenho da Ciência Jurídica (BRASIL, 2004 p. 2-3).

No entanto, para Moura, Tassigny e Silva (2018), o ensino jurídico encontra-se em uma crise didático-pedagógica, pois a maioria dos professores leciona com base na transmissão dos conteúdos (método catequético), que tem como consequência um aluno que não desenvolve a consciência crítica necessária para refletir sobre os temas discutidos.

\section{Educação a distância no Brasil: origens e especificidades}

Sobre a trajetória da educação a distância $(\mathrm{EaD})$ no Brasil, no âmbito das políticas públicas, Cruz e Lima (2019) apresentam os marcos considerados essenciais nesse processo que são a publicação da Lei de Diretrizes e Bases da Educação (LDB) n. . 9.394, de 1996, o Decreto n. ${ }^{\circ}$ 5.622, de 2005, e o Decreto n. ${ }^{\circ}$ 9.057, de 2017, dentre outros documentos, que influenciaram sobremaneira a configuração atual da educação a distância. 
Sobre o período pré-Lei de Diretrizes e Bases da Educação, Cruz e Lima (2019) ressaltam que apesar das primeiras ações voltadas à $\mathrm{EaD}$ no Brasil datarem do final do século XIX e atravessarem o século XX, o seu fortalecimento deu-se em 1978, com o uso da televisão como forma de difusão de conhecimento via Telecurso 2. ${ }^{\circ}$ grau da Fundação Roberto Marinho (FRM), em parceria com a Fundação Padre Anchieta (FPA).

Sobre o período pós-Lei de Diretrizes e Bases da Educação, as autoras destacam que em 1996, a educação a distância ganhou mais força com o Decreto n. ${ }^{\circ} 1.917$, de 27 de maio, que determinava, oficialmente, a criação da Secretaria de Educação a Distância e ao ser contemplada pela Lei de Diretrizes e Bases da Educação, n. ${ }^{\circ}$ 9.394/1996.

Assim, para Cruz e Lima (2019), foi na década de 1990 (NOVELLO, 2011, p. 40) que as instituições de ensino superior (IES) brasileiras começaram a implementar a EaD com o uso das tecnologias da informação e comunicação (TICs).

Sobre as regulamentações da EaD e seus efeitos pós-2005, Cruz e Lima (2019) relatam que apesar de as ações realizadas até 2005 terem incentivado a EaD no país, foi com a publicação do Decreto n. ${ }^{\circ}$ 5.622, de 19 de dezembro de 2005, regulamentando o artigo 80 da LDB, que ela ganhou força de maneira efetiva.

De acordo com Cruz e Lima (2019), percebe-se que o decreto possibilitou um crescimento significativo da $\mathrm{EaD}$, pois, pela primeira vez a modalidade passou a ocupar lugar de destaque em políticas educacionais, tornando-se, inclusive, política de Estado. Além da promulgação do Decreto n. ${ }^{0} 5.622$, de 2005, a expansão da EaD pública está relacionada a duas políticas cruciais para a EaD brasileira: a Universidade Aberta do Brasil (UAB) na educação superior e a Rede e-Tec Brasil na educação profissional técnica e tecnológica.

Em 2016, foram homologadas as Diretrizes e Normas Nacionais para a oferta de programas e cursos de Educação Superior na modalidade ensino a distância (EaD), estabelecidas na Resolução n. ${ }^{\circ}$ 1, de 11 de março, pela Câmara da Educação Superior do Conselho Nacional de Educação (CNE). 


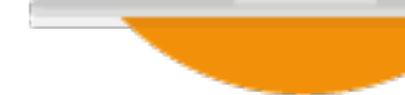

Essas diretrizes serviram de base para a criação do Decreto n. ${ }^{\circ} 9.057$, de 2017, que define que as instituições de ensino superior podem ampliar a oferta de cursos de graduação e pós-graduação a distância. (MEC, 2016).

Por fim, de acordo com Cruz e Lima (2019), constata-se que a EaD ainda sofre com uma regulamentação frágil, com a falta de critérios de qualidade e de insuficiência de mecanismos de regulação e controle estatais, o que vem dificultando a sua institucionalização.

\section{Desafios, dilemas e possibilidades da graduação em Direito na modalidade de EaD}

No que se refere a graduação em Direito e suas peculiaridades normativas, Mota, Tavares e Linhares (2018), destacam que a Resolução CNE/CES nº 9/2004, de 29 de setembro de 2004, estabelece as Diretrizes Curriculares Nacionais que organizam o curso de graduação em Direito, e está previsto como exemplos dos elementos estruturais do Projeto Pedagógico do curso, a abrangência na realização da interdisciplinaridade (artigo $\left.2^{\circ}, \S 1^{\circ}, I V\right)$, os modos de entre teoria e prática (artigo $2^{\circ}, \S 1^{\circ}, \mathrm{V}$ ), e o incentivo à pesquisa e à extensão, como prolongamentos da atividade de ensino (artigo $2^{\circ}, \S 1^{\circ}$, VIII).

No artigo $4^{\circ}$ orienta a formação profissional do bacharel em Direito, que deve promover habilidades e competências que incentivem a utilização de raciocínio jurídico, de argumentação, de persuasão e de reflexão crítica (inciso VI), além de capacitar o discente ao domínio de tecnologias e métodos para uma construção permanente do conhecimento jurídico (inciso VIII), destaque-se.

De acordo com a Portaria MEC $\mathrm{n}^{\mathrm{o}} 1.134$, de $1^{\mathrm{o}}$ de outubro de 2016, as instituições de ensino superior poderão ofertar, nos seus cursos presenciais, disciplinas integrantes do currículo na modalidade à distância (artigo $1^{\circ}$ ), sendo essa modalidade definida pela Portaria MEC $\mathrm{n}^{\circ}$ 4.059/2004 revogada, como sendo quaisquer atividades didáticas, módulos ou unidades de ensino-aprendizagem que sejam mediadas em diferentes suportes de tecnologias de comunicação remota $\left(\operatorname{artigo~} 1^{\circ}, \S 1^{\circ}\right)$.

A Portaria $\mathrm{n}^{\mathrm{o}} 1.134 / 2016$ orienta que, fica delimitado que a oferta de disciplinas, na modalidade à distância, não ultrapasse $20 \%$ (vinte por cento) da carga horária total do curso (artigo $1^{\circ}, \S^{\circ}$ ), incluindo nessa orientação os cursos de graduação em Direito. 
A Portaria ainda prevê que, na oferta das disciplinas na modalidade semipresencial, deverão ser observados os métodos e práticas de ensino-aprendizagem que possibilitem o uso integrado de tecnologias de informação e comunicação para a realização dos objetivos pedagógicos $\left(\operatorname{art} .2^{\circ}\right)$.

De acordo com Mota, Tavares e Linhares (2018), o Normativo sugere uma pedagogia centrada na autoaprendizagem, percebendo-se, nesse ponto, o enfoque da autonomia na produção de conhecimento pelo próprio aluno.

Da mesma Resolução CNE/CES n ${ }^{\circ}$ 9/2004, se verifica no artigo $3^{\circ}$, que o curso de graduação em Direito deverá garantir uma sólida formação geral, humanística e axiológica do seu graduando, evidenciando neste uma postura reflexiva e visão crítica, que lhe possibilite uma aprendizagem autônoma e dinâmica, e que lhe evidencie o desenvolvimento da cidadania, propiciando-lhe a argumentação, interpretação e valorização dos fenômenos jurídicos.

Na gestão 2013-2016, a Comissão Nacional de Educação Jurídica (CNEJ) da OAB, apresentou propostas (CNEJ, 2014) para o aperfeiçoamento do Marco Regulatório do Ensino Jurídico no país, estabelecendo o critério da "necessidade social" como requisito para autorização de oferta de curso de Direito, estipulando diversas condições para contemplar a referida autorização.

Segundo Mota, Tavares e Linhares (2018), há no documento a previsão excepcional para autorizações, quando a oferta se tratar de projeto de curso diferenciado e de alta qualificação, compatível com um corpo docente com titulação em nível de pós-graduação stricto sensu, e que haja a implementação dos Núcleos de Pesquisa, empreendendo a qualidade da estrutura curricular, dentre outros. Esta proposta alcança, inclusive, a alteração no texto da Resolução n. 9/2004, para a inclusão de novos conteúdos no atual currículo dos cursos de graduação em Direito, inserindo-se o Direito da Tecnologia da Informação, a Mediação, Conciliação e Arbitragem, Direitos Humano, dentre outros, com uma maior amplitude na oferta de disciplinas optativas que promoverão a autoaprendizagem, e que torna ainda mais efetiva, a possibilidade de inclusão da graduação em Direito na modalidade à distância

\section{SEMINÁRIO DE EDUCAÇÃO A DISTÂNCIA}


Nesse contexto, a modernização curricular da graduação em Direito faz-se necessária, bem como uma análise acerca do curso na modalidade à distância. De acordo com Mota, Tavares e Linhares (2018), o Conselho Nacional de Educação (CNE) propôs a modernização dos currículos da graduação do curso de Direito, no intuito de buscar a adaptação necessária daquilo que se ensina ao que se vê no cotidiano dos escritórios de advocacia e nas diversas realidades regionais, além de propor a visão da interdisciplinaridade, da internacionalização, da visualização sobre as relações étnico-raciais, indígenas e de gênero (BRASIL, 2018).

Segundo os autores, a proposta do CNE vem se desenvolvendo desde o ano de 2014, e teve a aprovação da Ordem dos Advogados do Brasil (OAB). Sem alterar a carga horária prevista para o curso de Direito, o Conselho sugere aumentar o enfoque regional e compor 50\% da carga horária com disciplinas optativas, esta última, possibilitando o aluno escolher conteúdos de acordo com a projeção profissional que pretende desenvolver (BRASIL, 2018).

A deliberação favorável à composição da carga horária dos cursos de graduação em Direito no percentual de $50 \%$ da estrutura curricular do curso, referente às disciplinas optativas, se implantadas na modalidade à distância, já se configurará num novo modelo de organização, oferta e o desenvolvimento dos cursos, que se verterá progressivamente no modelo dinamizado pela modalidade, ora comentada.

O critério argumentativo aplicado pela $\mathrm{OAB}$ nacional para tentar coibir possíveis autorizações na criação de cursos de Direito - bacharelado, na modalidade à distância, foi o crescimento desordenado dos cursos presenciais, sem o atendimento aos requisitos da necessidade social, conforme destacado em capítulo anterior (BRASIL, 2018). Com base nos dados coletados pela equipe da Associação Brasileira de Educação a Distância (Abed), no Censo EAD-BR realizado em 2016, no Brasil, confirmou-se que as instituições que oferecem EAD, em geral, já têm tradição de ensino presencial, fato que possibilita alcançar a qualidade desejável para o curso de Direito, graduação, à distância (ABED, 2016).

Percebe-se que a discussão proposta pela $\mathrm{OAB}$ perante o $\mathrm{CNE}$, relativo às mudanças nas diretrizes curriculares dos cursos de Direito, perpassam por questões distintas, e que não 


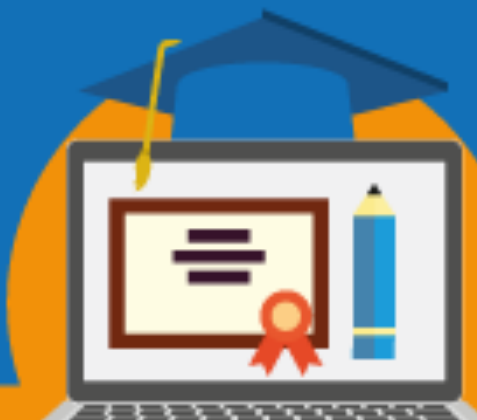

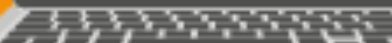

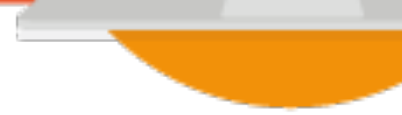

alcançam, ainda, o contexto acadêmico mais amplo da pesquisa e da extensão, pois, para a $\mathrm{OAB}$, a sua preocupação peculiar está na formação profissional do bacharel em direito, apto a avaliação do Exame da Ordem, enquanto o CNE, busca estimular o contato dos alunos do curso de direito, com os seus futuros empregadores.

Para Mota, Tavares e Linhares (2018), diante desse cenário, há o risco de que a oferta de disciplinas optativas pode ser aplicada de acordo com os interesses das instituições de ensino superior ou do próprio mercado de trabalho, dando margem à negligência com as disciplinas do Eixo de Formação Fundamental.

Enquanto a preocupação da $\mathrm{OAB}$ está na disseminação de cursos de Direito sem a qualidade acadêmica adequada, a legislação, que normatiza a oferta de cursos na modalidade à distância, é enfática em prever a realização de processos avaliativos, que, necessariamente terão a participação da Ordem dos Advogados do Brasil.

Para reflexão e análise sobre essas questões, Mota, Tavares e Linhares (2018), propõem o "Modelo Pedagógico da Universidade Aberta em Portugal". Nesse contexto as mudanças empreendidas pelas tecnologias de informação e comunicação são, em regra, grandes desafios para o sistema educacional e para os seus agentes envolvidos, em especial, os professores e alunos. Segundo os autores, o redimensionamento da construção do conhecimento, das formas comunicacionais e a incorporação de novos espaços de aprendizagem, são os aspectos elementares a serem observados quando da criação de ecossistemas virtuais que promovam a aprendizagem do aluno.

O modelo pedagógico da Universidade Aberta (UAb) de Portugal está pautado em quatro grandes linhas de força, estabelecidas para a educação a distância: a aprendizagem centrada no estudante, o primado da flexibilidade, o primado da interação e o princípio da inclusão digital. Essa linha de força tem aplicação compatível nas diretrizes consolidadas no artigo $3^{\circ}$, da Resolução CNE/CES n ${ }^{\circ}$ 9/2004, de 29 de setembro de 2004, que estabelece as Diretrizes Curriculares Nacionais que organizam o curso de graduação em Direito.

\section{SEMINÁRIO DE EDUCAÇÃO A DISTÂNCIA}




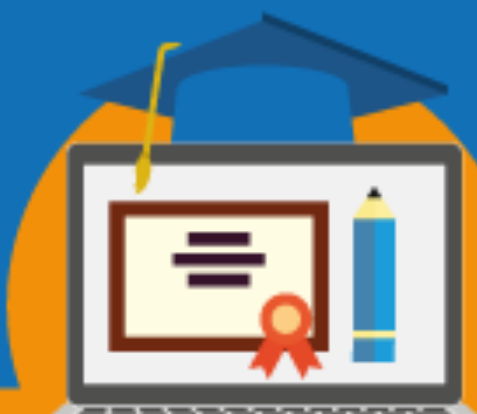

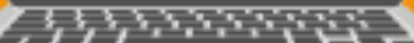

Portanto, para os autores, há um desafio antecedente às propostas anunciadas pelo Conselho Nacional de Educação e pela Ordem dos Advogados do Brasil, para as alterações nas diretrizes curriculares do curso de Direito, que é o de tornar mais dinâmico e participativo o processo de construção do conhecimento jurídico, mas, é evidente que a oferta das disciplinas optativas, compreendendo a largueza do conhecimento decorrente dessa projeção, pode ser consentida na modalidade à distância, o que leva o olhar do leitor ao primado da flexibilidade, predita no modelo pedagógico da UAb.

Nesse sentido, segundo Mota, Tavares e Linhares (2018), para os cursos de graduação em Direito do Brasil, considerando o modelo pedagógico proposto pela Universidade Aberta de Portugal, os primados expõem uma necessária ruptura do modelo educacional praticado pelas instituições de ensino superior, em sua grande maioria, pois contraria o tradicionalismo pedagógico que é característico dos cursos jurídicos no país.

Portanto, para aliar a proposta do Conselho Nacional de Educação (CNE), que pretende conectar os currículos dos cursos de Direito ao mercado local, num processo de regionalização e estímulo ao maior contato do aluno com o mercado empregador, e ao mesmo tempo, de compor $50 \%$ da carga horária com disciplinas optativas nos referidos cursos, a saída mais viável, a curto prazo, seria a de ofertar essa carga horária de graduação, na modalidade à distância.

\section{Considerações finais}

O objetivo geral desta investigação foi refletir e analisar sobre os desafios, dilemas e possibilidades da graduação em Direito na modalidade de educação a distância (EaD), partindo da perspectiva da necessidade de ressignificar o modo como os cursos de Direito conduzem o processo educativo, buscando encontrar garantias para que se tenha um ensino eficiente e de qualidade.

O presente texto enfatizou os avanços tecnológicos presentes nos processos de ensinoaprendizagem bem como destacou a possível aplicação da oferta de cursos semipresenciais de

\section{SEMINÁRIO DE EDUCAÇÃO A DISTÂNCIA}




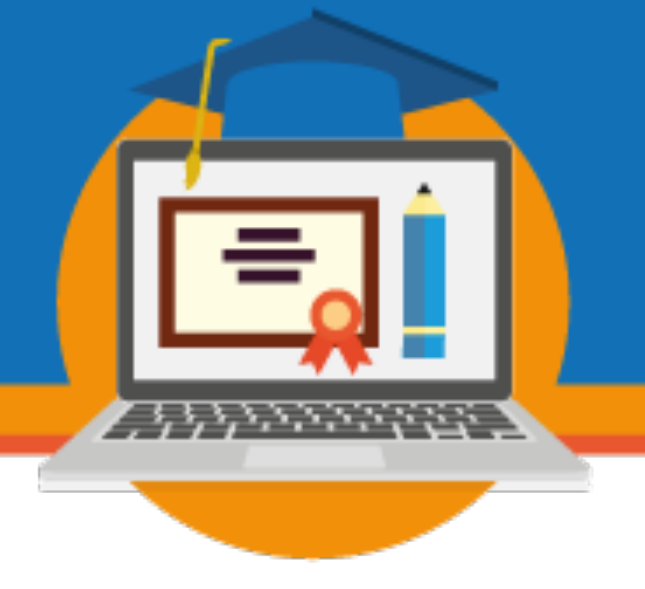

graduação em Direito, com o enfoque nos primados do modelo pedagógico da Universidade Aberta de Portugal.

A normatização legal para as diretrizes curriculares dos cursos jurídicos, no Brasil já prevê a inserção de conteúdos, nos processos de ensino e aprendizagem, com a utilização de meios e tecnologias de informação e comunicação, que ultrapasse o limite de $20 \%$ da carga horária total do curso ( Portaria $\mathrm{n}^{\mathrm{o}} 1.134 / 2016$ ), pois a Portaria $1.428 / 2018$, que dispõe sobre a oferta de disciplinas com metodologia a distância, em cursos de graduação presencial ofertados por IES, credenciadas pelo MEC que, conforme o art. $3^{\circ}$, o limite de $20 \%$ definido no art. $2^{\circ}$, poderá ser ampliado para até $40 \%$ para cursos de graduação presencial.

Nesse contexto, percebe-se também que há uma predisposição do Conselho Nacional de Educação (CNE) para a revisão das diretrizes nacionais curriculares do curso de direito, com o direcionamento de $50 \%$ da carga horária com disciplinas optativas, em consonância com os avanços tecnológicos. Assim, criou-se um ambiente propício para a inserção da oferta de cursos de graduação em Direito, na modalidade à distância.

\section{Referências}

ABMES. Associação Brasileira de Mantenedoras de Ensino Superior. Portaria $n^{\circ}$ 1134/2016. Disponível em: https://abmes.org.br/legislacoes/detalhe/1988/portaria-n1134. Acesso em: 11 jul. 2018.

ASSOCIAÇÃO BRASILEIRA DE EDUCAÇÃO À DISTÀNCIA (ABED). CensoEAD.BR - 2016/2017. Disponível em: http://abed.org.br/censoead2016/ Censo_EAD_2016_portugues.pdf. Acesso em: 19 jul.2018.

.Portaria MEC no 4059/2004. Disponível em: http://portal.mec.gov.br/ sesu/arquivos/pdf/nova/acs_portaria4059.pdf. Acesso em: 10 jul. 2018.

.Portaria MEC no 1428/2018. Disponível em: http://portal.mec.gov.br/index.php? option=com_docman \&view $=$ download $\&$ alias $=108231$-portaria1428\&category_slug=fevereiro-2019-pdf\&Itemid=30192

Resolução CNE/CES $\quad n^{\circ} \quad$ 9/2016. Disponível em: http://portal.mec.gov.br/cne/arquivos/pdf/rces09_04.pdf. Acesso em: 10 jul. 2018. 


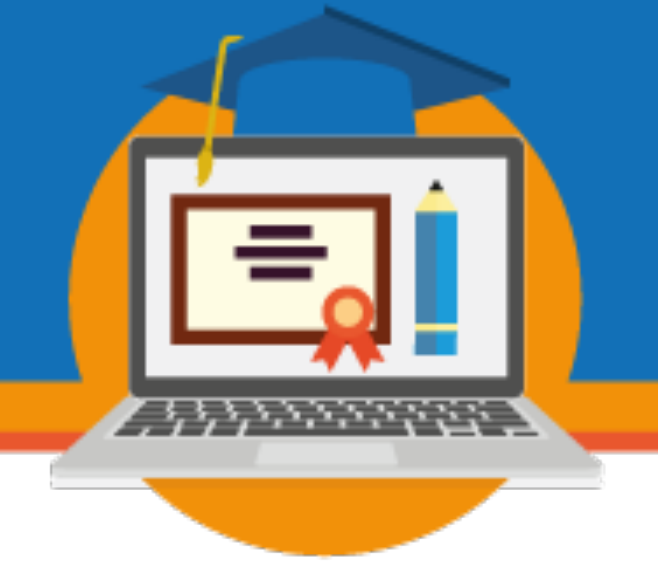

Planalto. Decreto $\quad \mathrm{n}^{\mathrm{o}} \quad 9.235 / 2017$ Disponível

em: http://www.planalto.gov.br/ccivil_03/_ato2015-2018/2017/decreto/D9235.htm. Acesso em: 12 jul. 2018.

. Planalto. Decreto n ${ }^{\circ}$ 9057/2017. Disponível em:

http://www.planalto.gov.br/ccivil_03/_ato2015-2018/2017/Decreto/D9057.htm.

Acesso em: 12 jul. 2018.

. Conselho Nacional de Educação (CNE). CNE propõe modernizar currículos de direito para aproximar estudantes dos escritórios. CLickPB. Julho/2018.

Disponível em: https://www.clickpb.com.br/brasil/cne-propoe-modernizar-curriculosdedireito-para-aproximar-estudantes-dos-escritorios-242589.html. Acesso em: 12 jul. 2018.

COMISSÃO NACIONAL DE EDUCAÇÃO JURÍDICA - CNEJ-OAB (Gestão 20132016). Migalhas. Disponível em: http://www.migalhas.com.br/arquivos/ 2014/2/art20140218-04.pdf. Acesso em: 12 jul. 2018.

CRUZ, J. R.; LIMA, D. da C. B. P. Trajetória da educação a distância no Brasil: políticas, programas e ações nos últimos 40 anos. Jornal de Políticas Educacionais. V. 13, n. 13. Abril de 2019.

MOTA, Marlton Fontes; LINHARES, Ronaldo Nunes; TAVARES, Thiago Passos. Graduação em Direito e o Ensino à Distância: Redimensionamento dos Cenários Educativos e Coaprendizagem em Rede. Simpósio Internacional de Educação e ComunicaçãoSIMEDUC, n. 9, 2018.

MOURA, Taísa Ilana Maia de; TASSIGNY, Mônica Mota; SILVA, Thomaz Edson Veloso. O USO DA TECNOLOGIA NO ENSINO JURÍDICO: O MÉTODO DO ENSINO HÍBRIDO NO CURSO DE DIREITO. Revista Univap, v. 24, n. 45, p. 70-85, 2018.

SANTOS, Catarina de Almeida. Educação Superior a Distância no Brasil: democratização da oferta ou expansão do mercado. RBPAE - v. 34, n. 1, p. 167 - 188, jan./abr. 2018. 